Western University

Scholarship@Western

Bone and Joint Institute

$5-31-2018$

\title{
Hybrid Polyester Self-Immolative Polymer Nanoparticles for Controlled Drug Release
}

\author{
Michael T. Gambles \\ Western University \\ Bo Fan \\ Western University \\ Aneta Borecki \\ Western University \\ Elizabeth R. Gillies \\ Western University
}

Follow this and additional works at: https://ir.lib.uwo.ca/boneandjointpub

Part of the Medicine and Health Sciences Commons

\section{Citation of this paper:}

Gambles, Michael T.; Fan, Bo; Borecki, Aneta; and Gillies, Elizabeth R., "Hybrid Polyester Self-Immolative Polymer Nanoparticles for Controlled Drug Release" (2018). Bone and Joint Institute. 502.

https://ir.lib.uwo.ca/boneandjointpub/502 


\title{
Hybrid Polyester Self-Immolative Polymer Nanoparticles for Controlled Drug Release
}

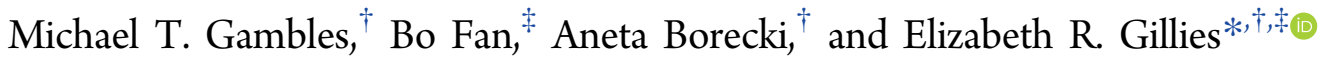 \\ ${ }^{\dagger}$ Department of Chemistry and the Centre for Advanced Materials and Biomaterials Research, The University of Western Ontario, \\ 1151 Richmond Street, London, Ontario N6A 3B7, Canada \\ ${ }^{\star}$ Department of Chemical and Biochemical Engineering, The University of Western Ontario, 1151 Richmond Street, London, \\ Ontario N6A 5B9, Canada
}

\section{Supporting Information}

\begin{abstract}
Delivery systems have been developed to address problematic properties of drugs, but the specific release of drugs at their targets is still a challenge. Polymers that depolymerize end-to-end in response to the cleavage of stimuliresponsive end-caps from their termini, commonly referred to as self-immolative polymers, offer high sensitivity to stimuli and have potential for the development of new high-performance delivery systems. In this work, we prepared hybrid particles composed of varying ratios of self-immolative poly(ethyl glyoxylate) (PEtG) and slowly degrading poly(D,L-lactic acid) (PLA). These systems were designed to provide a dual release mechanism consisting of a rapid burst release of drug from the PEtG domains and a slower release from the PLA domains. Using end-caps responsive to UV light and reducing thiols, it was found that triggered particles exhibited partial degradation, as indicated by a reduction in their dynamic light-scattering count rate that depended on the PEtG:PLA ratio. The particles were also shown to release the hydrophobic dye Nile red and the drug celecoxib in a manner that depended on triggering and the PEtG:PLA ratio. In vitro toxicity assays showed an effect of the stimuli on the toxicity of the celecoxib-loaded particles but also suggested it would be ideal to replace the sodium cholate surfactant that was used in the particle synthesis procedure in order to reduce the background toxicity of the delivery system. Overall, these hybrid systems show promise for tuning and controlling the release of drugs in response to stimuli.
\end{abstract}

\section{INTRODUCTION}

The controlled release of therapeutics using drug delivery systems has been studied in depth over the last several decades. $^{1-3}$ Drug delivery systems can provide improved solubility or dispersibility of hydrophobic drugs, improved bioavailability, and more specific targeting, leading to fewer adverse side effects. Polymers have been widely explored for drug delivery, as they can be engineered to assemble into a variety of nanostructures such as vesicles, micelles, and solidcore particles by tuning both their chemical structures and their processing conditions. ${ }^{4,5}$ Polymeric solid-core particles, composed of a hydrophobic polymer core that is stabilized in aqueous solution using a surfactant coating, are among the most widely investigated drug delivery systems due to their ease of preparation by various techniques such as emulsification or nanoprecipitation. ${ }^{6-8}$ A hydrophobic cargo molecule can be encapsulated within the hydrophobic cores of the particles during their preparation.

Thus far, most polymeric particles have been composed of biodegradable polyesters such as poly(lactic acid), poly(glycolic acid), poly(caprolactone), and their copolymers. ${ }^{9-11}$ While these have been effective at improving the delivery of therapeutics, the hydrolytic degradation of polyesters is inherently a random process, and it is challenging to control its rate. ${ }^{12}$ In some cases, degradation may be more rapid than desired, while in other cases it may be too slow. To address this limitation, stimuli-responsive particles have been developed and shown to release drug molecules in response to stimuli such as heat, reactive oxygen species, reducing agents, or changes in $\mathrm{pH}^{13,14}$

Over the past decade, a new class of stimuli-responsive polymers was introduced. Often termed self-immolative polymers (SIPs), these polymers undergo complete end-toend depolymerization in response to stimuli-mediated cleavage of end-caps from the polymer termini. ${ }^{15,16}$ This offers the potential to amplify responses to stimuli, making SIPs of significant interest for a wide range of applications including sensors, ${ }^{17-19}$ responsive plastics and coatings, ${ }^{20-22}$ lithography, ${ }^{23}$ and drug delivery. ${ }^{18,24-28}$ Backbones including polycarbamates, ${ }^{17,24}$ polyaldehydes, ${ }^{20,23,29-34}$ polycarbonates, ${ }^{35}$ polythiocarbamates, ${ }^{36}$ and poly(benzyl ether) $\mathrm{s}^{37}$ have been developed, and end-caps responsive to stimuli including light, ${ }^{25,26,31}$ thiols, $^{26,36}$ acid, $^{38}$ fluoride, ${ }^{20,21,39}$ heat, ${ }^{40,41}$ and $\mathrm{H}_{2} \mathrm{O}_{2}{ }^{19,42}$ have been studied.

Received: March 20, 2018

Accepted: April 27, 2018

Published: May 8, 2018 
Only a few studies thus far have explored the potential of SIPs for drug delivery. Our group demonstrated the triggered release of Nile red as a model drug from assemblies composed of poly(ethylene glycol) (PEG) block copolymers with a polycarbamate SIP based on 4-hydroxybenzyl alcohol and N,Ndimethylethylene diamine. ${ }^{24}$ Almutairi and co-workers prepared nanoparticles from the same polymer backbone capped with a UV light-responsive end-cap and studied the release of Nile red from these particles in response to UV and two-photon irradiation. $^{25}$ Liu and co-workers reported self-immolative vesicles based on polycarbamates composed of 4-aminobenzyl alcohol as the hydrophobic block and demonstrated vesicle disruption and the release of payloads including fluorophores, enzymes, and the drugs camptothecin and doxorubicin (Dox) in response to light or reducing conditions as stimuli. ${ }^{26}$ They also prepared amphiphilic hyperbranched polycarbamate-PEG copolymers and demonstrated the release of Dox that was covalently bound to the polymers as well as DNA that was complexed to cationic poly(2-(dimethylamino)ethyl methacrylate) chains conjugated to the periphery of the hyperbranched polymer. $^{18}$ Vallet-Regi, Manzano, and co-workers used polycarbamates as blocking agents to control drug release from mesoporous silica nanoparticles. ${ }^{28}$ Despite this progress, the release of potentially toxic quinone methides and azaquinone methides from these systems during their depolymerization is a possible drawback. ${ }^{43}$ To address this, we recently reported the study of micelles based on poly(ethyl glyoxylate) (PEtG)-PEG block copolymers. ${ }^{27}$ PEtG depolymerizes to ethyl glyoxylate, which is subsequently hydrolyzed to generate ethanol and glyoxylic acid (Figure 1a). Glyoxylic acid is a metabolic intermediate that can be processed in the liver and should be nontoxic in low concentrations. ${ }^{44}$ Previous work has demonstrated the nontoxicity of PEtG degradation products in a Caenorhabditis elegans (invertebrate) model. $^{45}$ We demonstrated that by simple tuning of the end-cap linker molecule between the PEG and PEtG blocks it was possible to easily change the stimulus to which the micelles responded, and the triggered release of doxorubin and curcumin was demonstrated. $^{27}$

We describe here an alternative approach for formulating drug delivery systems using PEtG. Using an emulsion method, we prepared sodium cholate-stabilized PEtG particles. Furthermore, in order to add an additional level of control over the drug release, we explored particles composed of blends of PEtG and poly(D,L-lactic acid) (PLA). It was envisioned that triggering of PEtG degradation would result in erosion and rapid drug release from the PEtG domains, leaving drug-loaded PLA for a sustained drug release. 6-Nitroveratryl carbonatecapped PEtG was selected for its rapid responsiveness to UV light and served as an ideal model system. ${ }^{31}$ Disulfide-capped $\mathrm{PEtG}^{38}$ was selected as a thiol-sensitive system, as elevated concentrations of reducing agents such as glutathione (GSH) are associated with the intracellular environment as well as hypoxic tumor tissue. ${ }^{46,47}$ The degradation of these hybrid particles in response to UV light and thiols was studied by dynamic light scattering (DLS) and the release of Nile red as a probe. The drug celecoxib was encapsulated in the hybrid particles, and its stimuli-responsive release was explored. Initial in vitro experiments were performed to explore the behavior of the system in cells. a)

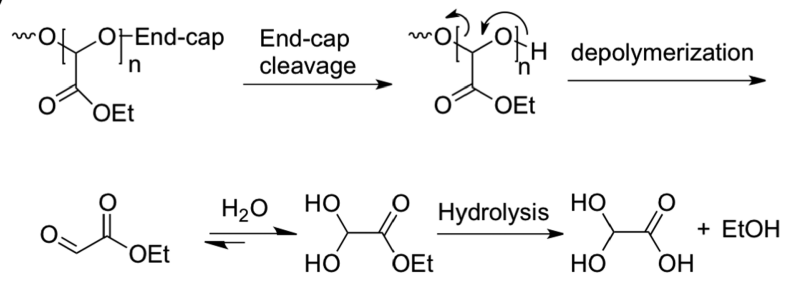

b)
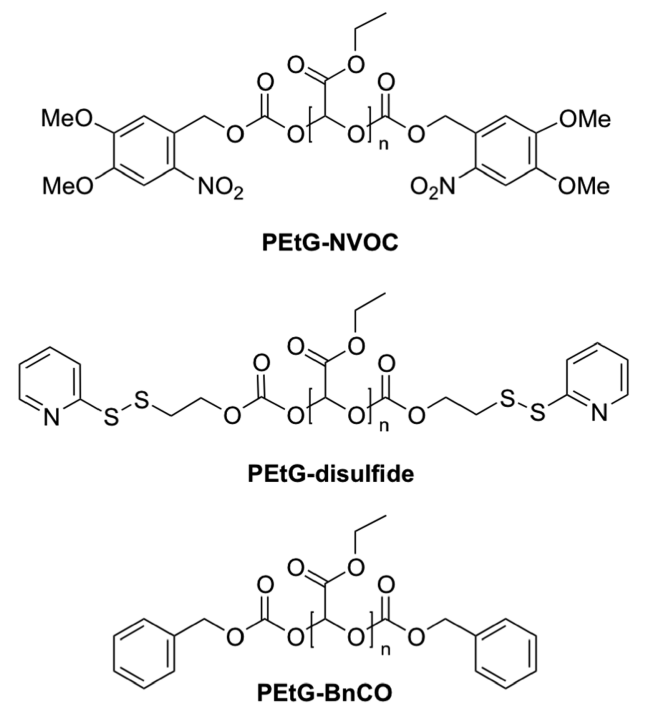

Figure 1. (a) Depolymerization scheme for PEtG. (b) Chemical structures of the stimuli-responsive and control PEtGs used in this study.

\section{RESULTS AND DISCUSSION}

Preparation and Characterization of PEtG and PEtGPLA Blends. PEtGs with different end-caps (Figure 1b) were synthesized as previously reported, ${ }^{31,38}$ and the characterization data for the specific batches used here are included in the Supporting Information. PEtG with a 6-nitroveratryl carbonate end-cap (PEtG-NVOC) was selected because the NVOC can be easily and cleanly removed using UV light. ${ }^{27,31}$ Although UV light is not practical for most in vivo applications, this serves as a valuable model. PEtG with a disulfide end-cap (PEtG-disulfide) was selected because it can be triggered using reducing thiols via an initial reduction of the disulfide, followed by cyclization of the resulting thiol to produce a cyclic thiocarbonate, releasing uncapped PEtG. ${ }^{38}$ Increased concentrations of the reducing agent glutathione are found in intracellular compartments and in hypoxic tumor tissue, potentially allowing for the selective release of drugs in these environments. ${ }^{48,49}$ A control PEtG had a benzyl carbonate end-cap (PEtG-BnCO) that was not expected to be specifically responsive to stimuli but contained the same carbonate linkage to the PEtG terminus as the other polymers. ${ }^{31}$

In addition to the pure polymers, blends of PLA with the PEtGs were also studied. Ratios of 9:1, 7:3, and 1:1 PEtG:PLA were prepared. Lower ratios of PEtG:PLA were not explored because it was anticipated that they would exhibit primarily nonstimuli-responsive behavior. They were prepared by codissolving the polymers in $\mathrm{CH}_{2} \mathrm{Cl}_{2}$. After removing the solvent, the blends were characterized by thermogravimetric analysis (TGA) and differential scanning calorimetry (DSC). These experiments utilized PEtG-NVOC, which behaves very 
similarly to the other PEtGs in terms of its thermal properties. ${ }^{38}$ TGA showed that in agreement with the literature pure PLA was stable up to $\sim 300{ }^{\circ} \mathrm{C}$ (Figure 2a). ${ }^{50}$ Pure PEtG with the

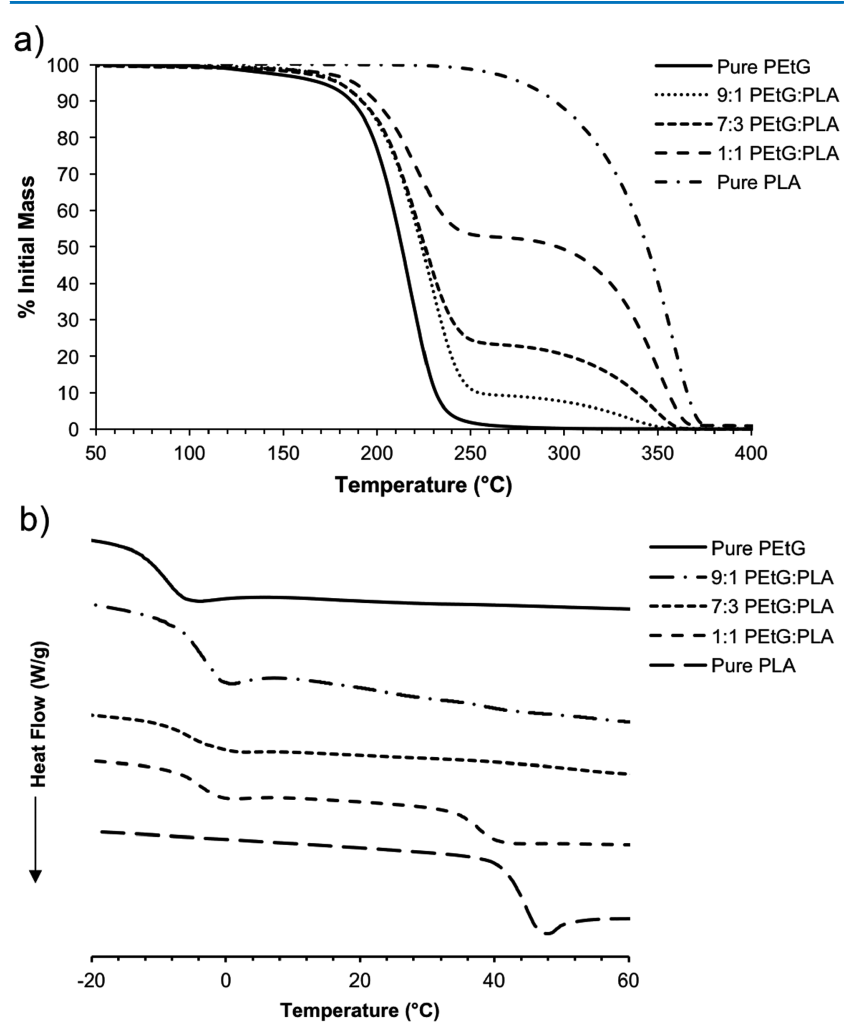

Figure 2. Thermal characterization data for PEtG-NVOC, PLA, and their blends: (a) thermogravimetric analysis and (b) differential scanning calorimetry.

NVOC end-cap was stable up to $200{ }^{\circ} \mathrm{C}$, also in agreement with the reported value. ${ }^{31}$ PEtG is less thermally stable than PLA due to its susceptibility to depolymerize. A two-step thermal degradation was observed for each of the three blends, and the mass fractions lost in each step were consistent with the relative ratios of polymers in the blends. DSC analysis showed that the two polymers were mostly phase separated in the blends as distinct glass transition temperatures $\left(T_{\mathrm{g}}\right)$ were observed for each of PEtG and PLA (Figure 2b, Table S2). However, the increase in the PEtG $T_{\mathrm{g}}$ from -8 to $-1{ }^{\circ} \mathrm{C}$ and simultaneous decrease in the PLA $T_{\mathrm{g}}$ from 46 to $40{ }^{\circ} \mathrm{C}$ as the PEtG content decreased to $50 \%$ suggested that some degree of mixing between the two polymers also occurred.

Particle Preparation. Particles were prepared by an emulsion-evaporation procedure. Various parameters including the surfactant identity, surfactant and polymer concentration, and sonication time were investigated with the aim of preparing particles of each polymer blend composition with diameters less than $200 \mathrm{~nm}$ and acceptable $(<0.3)$ polydispersity indices (PDI), to allow potential in vivo circulation. Using PEtG-NVOC, it was found that using sodium cholate at $5 \mathrm{mg}$ / $\mathrm{mL}$ in $\mathrm{H}_{2} \mathrm{O}$, PEtG at $10 \mathrm{mg} / \mathrm{mL}$ in $\mathrm{CH}_{2} \mathrm{Cl}_{2}$, a $10: 1$ ratio of $\mathrm{H}_{2} \mathrm{O}: \mathrm{CH}_{2} \mathrm{Cl}_{2}$, and three $30 \mathrm{~s}$ periods of sonication it was possible to prepare particles with $Z$-average diameters ranging from 128 to $144 \mathrm{~nm}$ and PDIs ranging from 0.11 to 0.26 as measured by DLS (Figure 3a, Table 1). While a relatively high mass ratio of 5:1 sodium cholate:polymer was used to stabilize the emulsion of small droplets during the preparation, after dialysis purification of the particles it was found that the ratio was $\sim 1.5: 1$. No significant trends were observed regarding the effects of the PEtG:PLA ratio. TEM imaging confirmed that the particles all had solid spherical morphologies (Figure $3 b-f$ ). The diameters observed by TEM were smaller than those measured by DLS, which can likely be attributed to the dried versus hydrated states of the particles in these different analyses as well as to possible aggregation in suspension. This procedure was also applied to blends of PEtG-disulfide and PEtG-BnCO with PLA, and the sizes and PDIs were very similar (Figures S4-S5, Tables S3-S4). The stabilities of the pure PEtGNVOC and pure PEtG-disulfide particles were also studied in mouse serum over $48 \mathrm{~h}$ at $37{ }^{\circ} \mathrm{C}$. The particles underwent a gradual increase in diameter over the course of the experiment, suggesting some degree of interactions with proteins and possible aggregation, but were relatively stable for the first several hours (Figures S6-S7).

Triggered Particle Degradation. First, DLS was used to study the degradation of the particles in response to stimuli. The DLS count rate is proportional to both the number of scattering particles in suspension and their mass if the attenuator of and laser position are fixed at constant values. A decrease in either the mass or number of particles arising from degradation would lead to a reduction in the count rate. Keeping the attenuator fixed, the count rate was measured initially and then at time points after introduction of the stimuli. For the PEtG-NVOC particles, the stimulus was the application of $2.8 \mathrm{~mW} / \mathrm{cm}^{2}$ of light radiation for $30 \mathrm{~min}$, as we have previously found this irradiation time to be sufficient to achieve complete end-cap cleavage for other systems at similar concentration. $^{27,31}$ For PEtG-disulfide particles, $7.7 \mathrm{mM}$ dithiothreitol (DTT) was added as a reducing agent, as this concentration was effective in triggering the depolymerization of assemblies based on PEtG block copolymers. ${ }^{27}$ Control experiments involved the application of stimuli to nonresponsive $\mathrm{PEtG}-\mathrm{BnCO}$ control particles to account for any nonspecific effects of the stimuli as well as background degradation.

For particles with each ratio of PEtG-NVOC:PLA, there was a rapid decrease in count rate over the first hour following UV irradiation that likely corresponded to degradation (Figure 4a). In addition, there were plateaus in the count rates at percentages corresponding approximately to the percentage of PLA in the particles. Pure PEtG particles approached zero counts at the $24 \mathrm{~h}$ time point; 9:1 PEtG-NVOC:PLA particles degraded to $\sim 10 \%$ of their original count rate and then remained constant; 7:3 PEtG-NVOC:PLA particles plateaued at $\sim 30 \%$ of the initial count rate; and $50 \mathrm{wt} \%$ of PLA particles plateaued at $\sim 50 \%$ of the initial count rate. Examination of the $Z$-average diameter and PDI for a representative pure PEtGNVOC particle sample showed large fluctuations in diameter and an increase in PDI, consistent with a major disruption of the particles (Table S5). In contrast, the diameter and PDI of 1:1 PEtG-NVOC:PLA particles underwent only minor fluctuations, suggesting that the particles were still largely intact due to the remaining PLA (Table S6). Light scattered from the pure PLA particles remained constant at $100 \%$ of the original counts over the $24 \mathrm{~h}$ period, suggesting that the system was stable over this time period. Furthermore, the application of UV light to the control PEtG-BnCO:PLA particles did not lead to any significant changes in count rate, demonstrating the specificity of the stimulus. 
a)
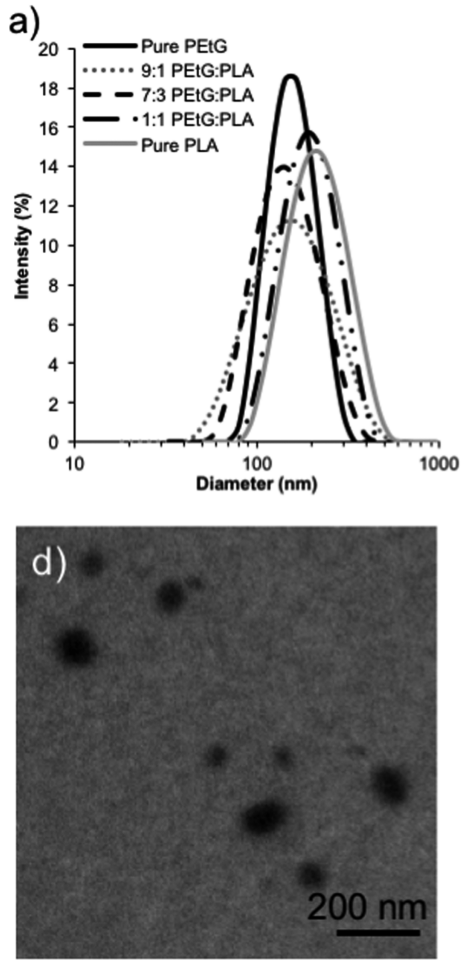
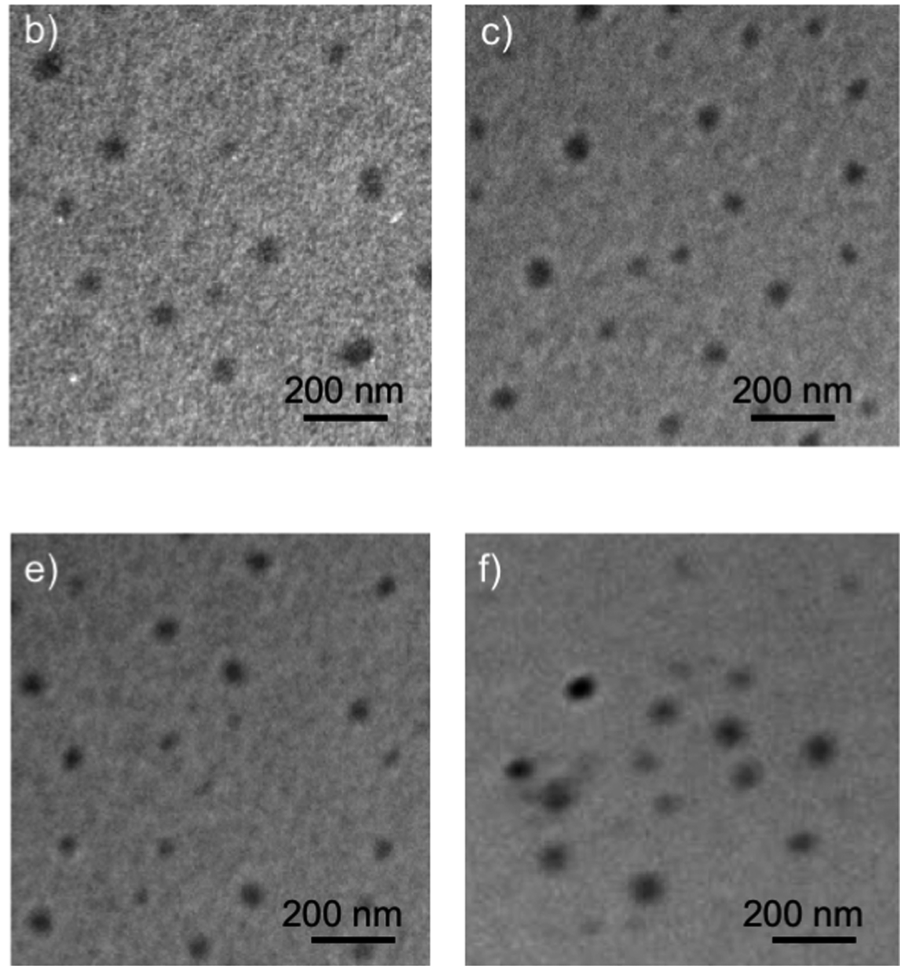

Figure 3. (a) DLS intensity distributions for particles prepared from PEtG-NVOC and PLA. (b-f) TEM images of particles prepared from PEtGNVOC and PLA: (b) pure PEtG; (c) 9:1 PEtG:PLA; (d) 7:3 PEtG:PLA; (e) 1:1 PEtG:PLA; and (f) pure PLA.

Table 1. Z-Average Diameters and PDI Values Measured by Dynamic Light Scattering for Particles Prepared from PEtG-NVOC and PLA

\begin{tabular}{lcc}
\multicolumn{1}{c}{ blend } & Z-average diameter $(\mathrm{nm})$ & PDI \\
pure PEtG & $144 \pm 13$ & $0.19 \pm 0.07$ \\
9:1 PEtG:PLA & $137 \pm 19$ & $0.26 \pm 0.11$ \\
7:3 PEtG:PLA & $128 \pm 7$ & $0.11 \pm 0.03$ \\
1:1 PEtG:PLA & $133 \pm 8$ & $0.12 \pm 0.03$ \\
pure PLA & $132 \pm 10$ & $0.13 \pm 0.04$ \\
\hline
\end{tabular}

As observed in our previous work with $\mathrm{PEtG}-\mathrm{PEO}$ block copolymer assemblies, ${ }^{27}$ the reduction in count rate occurred more slowly for the PEtG-dilsulfide:PLA systems in response to DTT (Figure 4b). This may result from the reduction reaction being slower than the photochemical end-cap cleavage. In addition, DTT is likely only able to react with end-caps at the particle surface, whereas UV light can penetrate the particles to some extent. Again, the particles with higher PEtG content exhibited larger reductions in the count rate over the experiment in general, corresponding to more complete degradation. Both pure PEtG-dilsulfide and 1:1 PEtGdisulfide:PLA particles underwent only minor fluctuations in $Z$-average diameter and PDI, suggesting that even while PEtG was eroded, resulting in a decrease in count rate, there were still particles remaining at $48 \mathrm{~h}$ (Tables S7-S8). The count rates from the pure PLA particles and all of the PLA:PEtG-BnCO particles remained near $100 \%$ of their original values over $48 \mathrm{~h}$.

The particle degradation was also studied using a fluorescent probe. Nile red is a hydrophobic dye that is highly fluorescent in hydrophobic environments but undergoes aggregation and fluorescence quenching in water. $^{51,52}$ Therefore, Nile red encapsulated within the particles fluoresces, and as it is released into the surrounding aqueous environment, the fluorescence
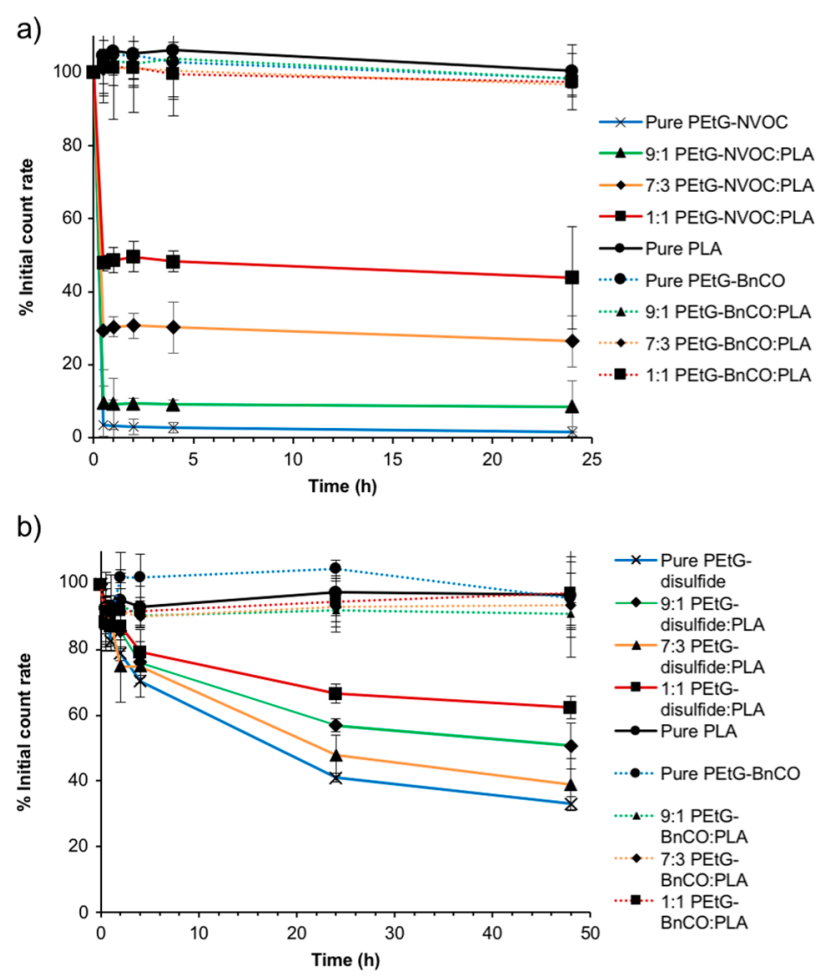

Figure 4. Count rate as a function of time after application of stimulus for: (a) particles composed of PEtG-NVOC:PLA or controls PEtGBnCO:PLA, where the stimulus was UV light and (b) particles composed of PEtG-disulfide:PLA or controls PEtG-BnCO:PLA, where the stimulus was DTT. The error bars correspond to standard deviations.

decreases. Nile red was encapsulated using the same particle preparation method described above except that $1 \mathrm{wt} \%$ of Nile 
red relative to polymer was incorporated into the $\mathrm{CH}_{2} \mathrm{Cl}_{2}$ phase. The initial fluorescence intensity was measured for each sample, and then UV light and DTT were applied as stimuli to PEtG-NVOC:PLA, PEtG-disulfide:PLA, and PEtG-BnCO:PLA particles as described above, and the fluorescence was measured over $24 \mathrm{~h}$. PEtG-NVOC:PLA particles exhibited a significant burst release of Nile red within the first hour after being exposed to UV light (Figure 5a). This can be attributed
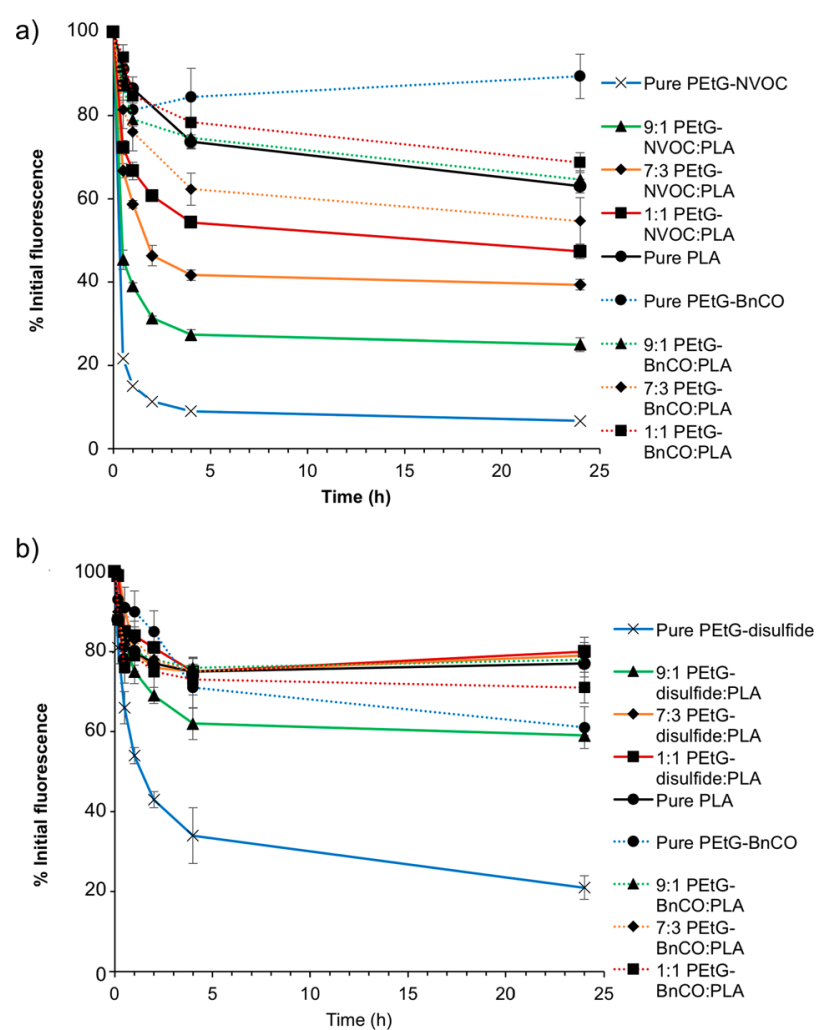

Figure 5. Fluorescence of the encapsulated hydrophobic probe Nile red as a function of time after application of stimulus for: (a) particles composed of PEtG-NVOC:PLA or control PEtG-BnCO:PLA, where the stimulus was UV light and (b) particles composed of PEtG-disulfide:PLA or control PEtG-BnCO:PLA, where the stimulus was DTT. The error bars correspond to standard deviations.

to the PEtG fraction of the particles being degraded. Similar to the DLS study, the fluorescence plateaued at higher percentages of the initial fluorescence as the PLA content of the particles increased. This suggests that it may be possible to selectively release a payload from the PEtG phase of the particles, while retaining the load in the PLA phase. After application of light to PEtG-BnCO:PLA particles, small reductions in the Nile red fluorescence were observed. This could be attributed to some background degradation of these systems, such as hydrolysis of the carbonate linkage between the end-cap and polymer, which would induce depolymerization. However, based on the DLS results described above, it likely corresponds to the passive diffusion of some Nile red from the peripheries of the particles or other factors that would alter the environment of Nile red.

As observed in the DLS study, Nile red release from the PEtG-disulfide:PLA particles following application of DTT was slower than for the light-responsive particles (Figure $5 b$ ). Again, this can likely be attributed to slower end-cap cleavage. However, this experiment also suggested that the extent of Nile red release was dependent on the PLA content. The levels of release from the PEtG-BnCO:PLA particles treated with DTT were similar to those observed following UV irradiation of the same particles. Overall, the DLS and Nile red release data show that it is possible to trigger degradation of the particles specifically by matching the stimulus with the end-cap and that it appears possible to trigger different percentages of degradation by tuning the PLA content in the particles.

Drug Loading and Triggered Release. Celecoxib was selected as an initial drug for investigating loading and release. It is a widely used nonsteroidal anti-inflammatory and has shown potential in cancer therapy. ${ }^{53,54}$ However, it exhibits low aqueous solubility and adverse gastrointestinal and cardiac effects when administered systemically. ${ }^{55,56}$ It was loaded into PEtG-NVOC:PLA, PEtG-disulfide:PLA, and PEtG-BnCO:PLA particles during their preparation by the addition of $30 \mathrm{wt}$ $\%$ of drug relative to polymer in the $\mathrm{CH}_{2} \mathrm{Cl}_{2}$ phase of the emulsion. Unloaded drug was removed by filtration and dialysis. The loading efficiencies ranged from 17 to $33 \%$ and the drug content from 4.9 to 8.8 wt \%. However, there were no statistically significant differences between the loadings of the different PEtG:PLA ratios (Table S9). The particle diameters were very similar to those of the unloaded particles described above (Tables S10-S12, Figures S8-S10).

Celecoxib release in response to UV light and DTT was investigated for the PEtG-NVOC:PLA and PEtG-disulfide:PLA systems, respectively, with the absence of stimuli and the application of stimuli to $100 \%$ PEtG-BnCO:PLA particles serving as controls. Initially, measurement of the released celecoxib posed a significant challenge due to the low water solubility of this drug. Upon application of the stimuli, the scattering of the suspension clearly decreased, indicative of degradation, but at the same time, the celecoxib precipitated (Figure S11). Due to this precipitation, use of a protocol involving dialysis into buffer resulted in measurement of the precipitated drug's dissolution rate rather than its actual release. The addition of Polysorbate 20, which we have used successfully with celecoxib in other studies in our lab, resulted in rapid release from control systems, suggesting that it destabilized the particles. Thus, the released and precipitated drug was instead centrifuged, dissolved in $\mathrm{CH}_{3} \mathrm{CN}$, and then quantified by UV-visible spectroscopy based on its absorbance at $253 \mathrm{~nm}$.

Application of UV light as a stimulus to the PEtG-NVOC systems resulted in a rapid release of celecoxib (Figure 6a). The percentage of released drug ranged from 15 to $82 \%$ in the first $30 \mathrm{~min}$, depending on the PEtG-NVOC:PLA ratio. Over the first 4 h, $26-89 \%$ of celecoxib was released. It is possible that the remaining $\sim 10 \%$ of the drug in the case of the pure PEtGNVOC system can be solubilized by the sodium cholate surfactant in the system. The percentage of drug released depended on the PEtG:PLA ratio, with higher PEtG content generally leading to increased drug release. However, more release was observed for the $1: 1$ system than for the 7:3 system, and the reason for this is not clear. Less release was observed from pure PLA particles (Figure 6a), controls consisting of nonirradiated PEtG-NVOC:PLA or UV-irradiated particles composed of PEtG-BnCO:PLA (Figure 6b). Interestingly, the irradiated particles generally had higher release than the nonirradiated particles, suggesting the possibility of a nonspecific reaction involving UV light. However, this was not observed in the DLS or Nile red experiments.

The addition of DTT to the PEtG-disulfide systems also resulted in the rapid release of celecoxib with similar trends 
a)

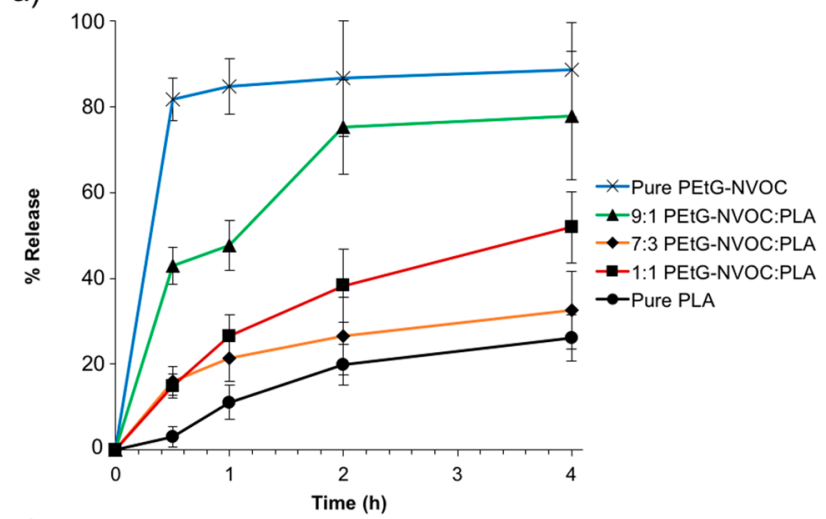

c)

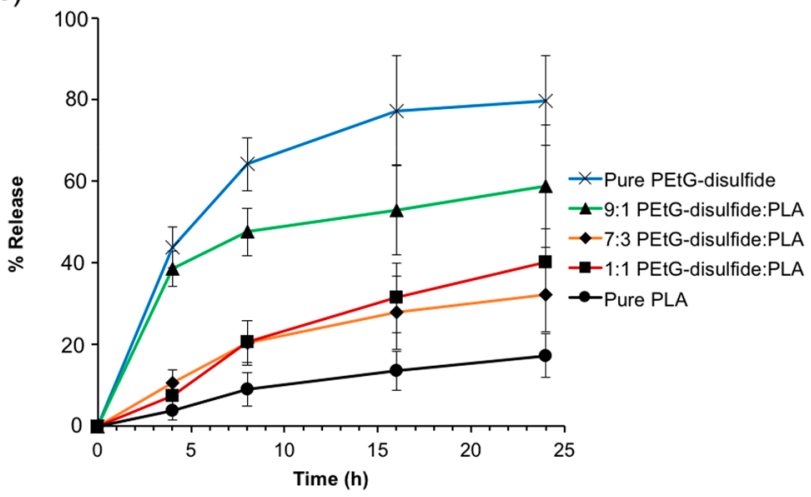

b)

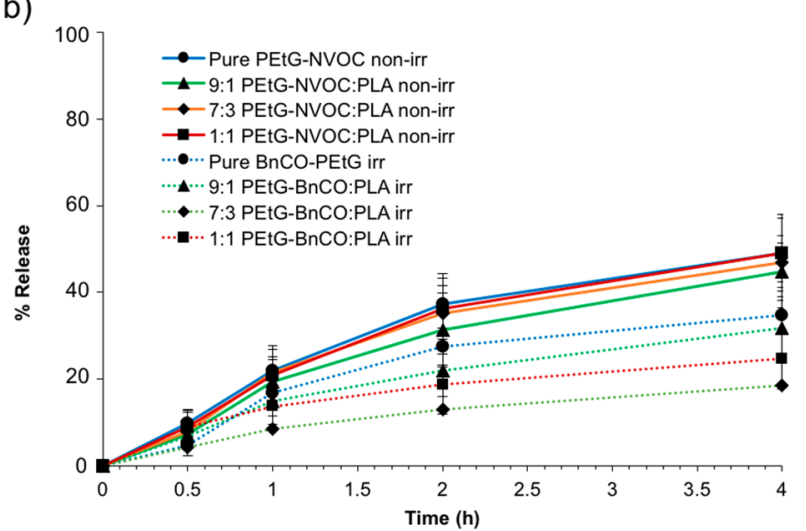

d)

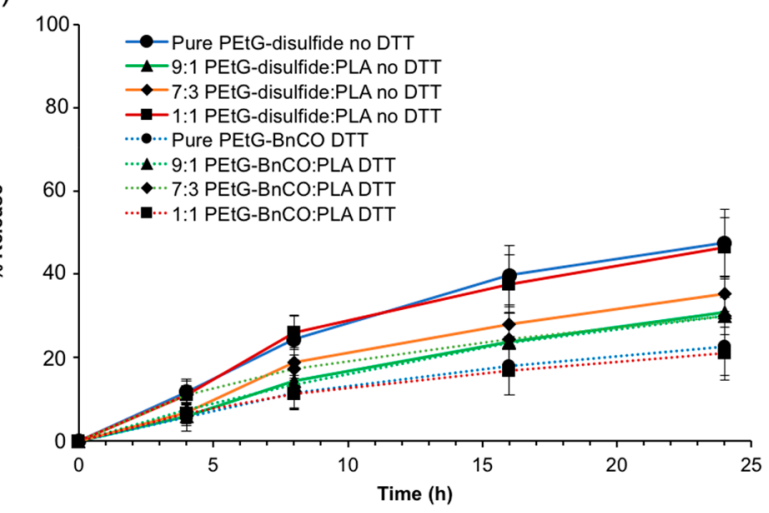

Figure 6. Celecoxib release as a function of time from (a) PEtG-NVOC:PLA particles irradiated with UV light; (b) PEtG-NVOC:PLA particles not triggered with UV light (non-irr) and control PEtG-BnCO:PLA particles irradiated with UV light (irr); and (c) PEtG-disulfide:PLA particles treated with DTT; (d) PEtG-disulfide:PLA particles not treated with DTT (no DTT) and control PEtG-BnCO:PLA particles treated with DTT (DTT). The error bars correspond to standard deviations.

observed with respect to the PEtG:PLA ratio as for the PEtGNVOC systems (Figure 6c). However, consistent with the DLS and Nile red studies, this release was slower than for the UV light-triggered release, with $7-44 \%$ of celecoxib released over the first $4 \mathrm{~h}$ and $32-80 \%$ released over $24 \mathrm{~h}$, again suggesting end-cap cleavage as the rate-limiting step. Again, control PLA particles (Figure 6c), PEtG-disulfide:PLA without DTT added and PEtG-BnCO:PLA (Figure 6d) with DTT added, exhibited slower release than the triggered systems. Nevertheless, the level of release from the control systems appeared to be relatively high, ranging from 18 to $49 \%$ over $4 \mathrm{~h}$ in the UV light experiment and $21-46 \%$ over $24 \mathrm{~h}$ in the DTT experiment. For this reason, we assessed the composition of the precipitated and centrifuged material from the 4 and $24 \mathrm{~h}$ time points by dissolving it in $\mathrm{CD}_{3} \mathrm{CN}$ and analyzing it by ${ }^{1} \mathrm{H}$ NMR spectroscopy (Figures S12-S20). By comparison of the spectra with those of celecoxib, PLA, and PEtG, it was found that after application of DTT to the PEtG-disulfide:PLA particles the pellet was primarily composed of celecoxib and not polymer, confirming its release from the particles and effective isolation by centrifugation. On the other hand, the pellets obtained from PEtG-disulfide:PLA particles not exposed to DTT or PEtGBnCO:PLA particles exposed to DTT contained mostly intact PEtG and PLA, indicating that some drug-loaded particles were destabilized and isolated during the centrifugation procedure, resulting in apparent release percentages for the controls that are likely higher than the true celecoxib release rates. Thus, the true leakage rates of celecoxib from the untriggered particles are likely lower than those reflected in Figures $6 \mathrm{~b}$ and $6 \mathrm{~d}$.
Nevertheless, this was still the most effective protocol to measure and demonstrate the triggered release of celecoxib from these systems and the ability to tune the release profile by tuning the PLA content.

In Vitro Studies. As noted above, celecoxib has been shown to exhibit anticancer properties, and there is value in releasing anticancer drugs specifically in cancer cells in order to mitigate the side effects that can result from their systemic administration. ${ }^{53}$ Therefore, the MDA-MB-231 breast cancer cell line was selected to evaluate the toxicities of different particles in both the absence and presence of stimuli using a 3(4,5-dimethylthiazol-2-yl)-2,5-diphenyltetrazolium bromide (MTT) assay. This study focused on the systems composed of pure PEtG rather than blends with PLA, in order to maximize the effect of the stimuli.

Following a $48 \mathrm{~h}$ incubation of the drug with cells, free celecoxib was found to have an $\mathrm{IC}_{50}$ value of $\sim 30 \mu \mathrm{g} / \mathrm{mL}$ in this cell line (Figure 7a). When celecoxib-loaded PEtG-NVOC particles were incubated with the cells for $48 \mathrm{~h}$ in the absence of any stimuli, they were found to be somewhat less toxic than the free drug, with an $\mathrm{IC}_{50}$ value near the maximum concentration studied of $\sim 75 \mu \mathrm{g} / \mathrm{mL}$ (concentration of loaded drug). On the other hand, when celecoxib-loaded PEtG-NVOC particles were incubated with the cells for $24 \mathrm{~h}$ (to allow uptake into cells), irradiated with $360 \mathrm{~nm}$ light (LED flashlights, $90 \mathrm{~mW}$ / $\mathrm{cm}^{2}$ ) for $15 \mathrm{~min}$, and then incubated an additional $24 \mathrm{~h}$, the $\mathrm{IC}_{50}$ was reduced to $\sim 30 \mu \mathrm{g} / \mathrm{mL}$, similar to that of free celecoxib. This is consistent with the release of drug from the system. It should be noted that cells exposed to $360 \mathrm{~nm}$ light, 

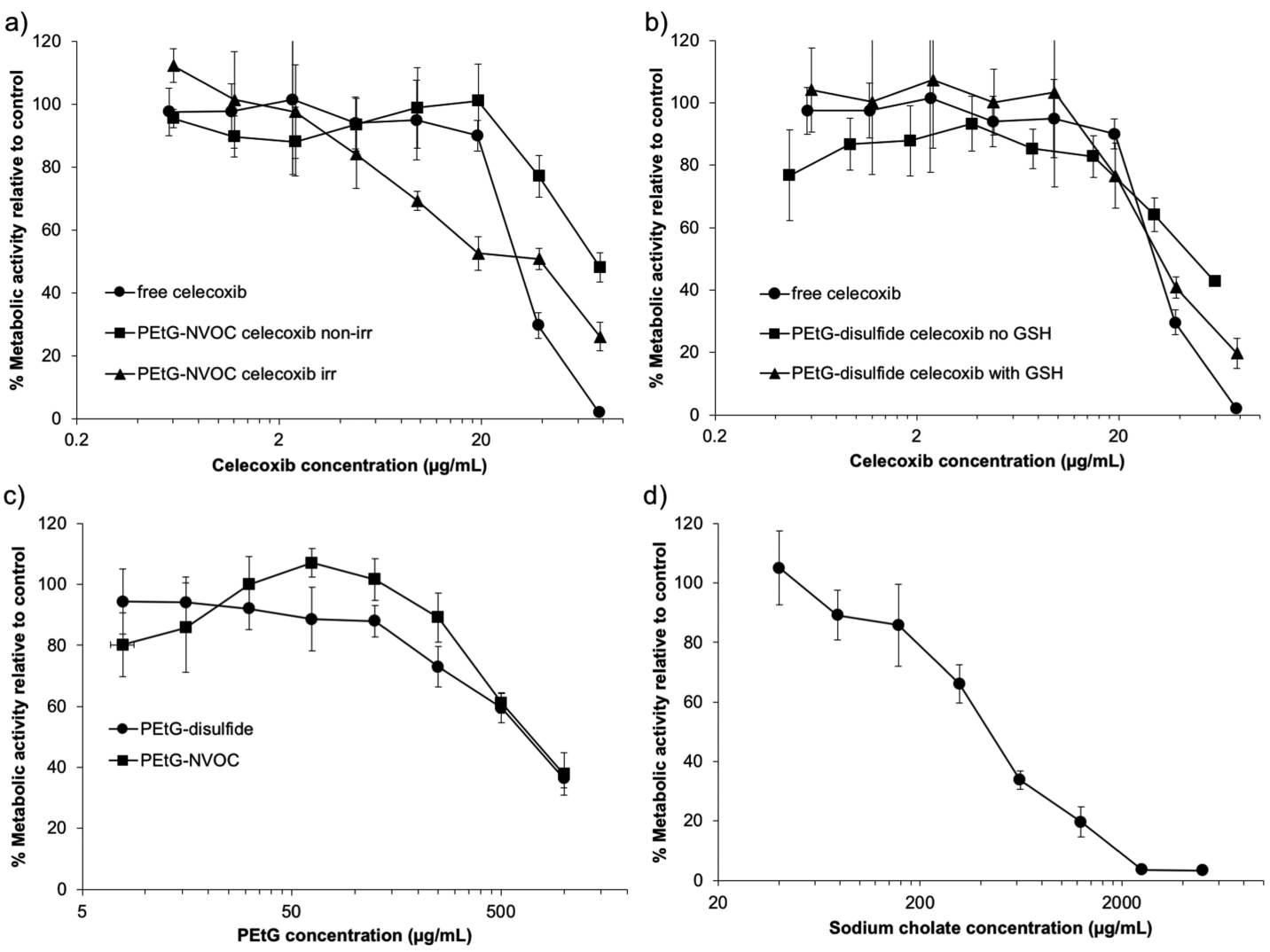

Figure 7. Metabolic activities, measured by MTT assays, of MDA-MB-231 cells following $48 \mathrm{~h}$ exposure to varying concentrations of (a) free celecoxib compared with celecoxib encapsulated in PEtG-NVOC particles without stimulus or with UV light applied for $15 \mathrm{~min}$ at $24 \mathrm{~h}$; (b) free celecoxib compared with celecoxib encapsulated in PEtG-disulfide particles without stimulus or with $10 \mathrm{mM}$ glutathione added at $24 \mathrm{~h}$; (c) particles composed of either PEtG-NVOC or PEtG-disulfide without drug; and (d) sodium cholate. The error bars correspond to standard deviations.

but no particles, did not exhibit any significant reduction in metabolic activity relative to nonirradiated cells, showing that this short irradiation process did not alone lead to toxicity. The toxicity of PEtG-NVOC particles without drug was also studied. The particles began to exhibit some toxicity at concentrations of $500 \mu \mathrm{g} / \mathrm{mL}$ and above (Figure 7c). Initially this was surprising as the PEtG and its degradation products were expected to be benign. However, when we studied the toxicity of the free sodium cholate, the surfactant used to stabilize the particles, we found that it began to cause toxicity at $\sim 300 \mu \mathrm{g} / \mathrm{mL}$ (Figure $7 \mathrm{~d}$ ). Based on mass recovery studies, we found that our particles were composed of $\sim 1.5: 1$ mass ratio of sodium cholate:PEtG. Therefore, despite cholic acid being one of the major bile acids produced in the liver, in this assay it is likely that most of the toxicity arose from the sodium cholate. In addition, based on the drug loading of $\sim 8 \mathrm{wt} \%$ for the PEtG-NVOC system $(1000 \mu \mathrm{g} / \mathrm{mL}$ of PEtG-NVOC needed to deliver $80 \mu \mathrm{g} / \mathrm{mL}$ of celecoxib), some of the toxicity arising from the nonirradiated celecoxib-loaded PEtG-NVOC system (Figure 7a) likely resulted from the delivery system itself (due to the cholate). The effect of the UV light would perhaps be larger were this not the case.

The PEtG-disulfide system was studied in a similar manner, except that in this case the reducing agent glutathione $(10 \mathrm{mM})$ was added as the stimulus following $24 \mathrm{~h}$ of incubation, and then the system was incubated for an additional $24 \mathrm{~h}$. As for the PEtG-NVOC system, the triggered system and free celecoxib had similar $\mathrm{IC}_{50}$ values of $\sim 30 \mu \mathrm{g} / \mathrm{mL}$, while the celecoxibloaded PEtG-disulfide without GSH added had a somewhat higher $\mathrm{IC}_{50}$ value of $\sim 60 \mu \mathrm{g} / \mathrm{mL}$ (Figure $7 \mathrm{~b}$ ). Thus, it appears that the GSH has a modest effect.

\section{CONCLUSIONS}

Blends of PLA with self-immolative PEtG were studied for the preparation of drug delivery particles. UV light-responsive, thiol-responsive, and nonresponsive control end-caps were used. Thermal studies suggested that PEtG and PLA were mainly phase separated, as $T_{\mathrm{g}}$ values of both blocks were observed using DSC. Using an emulsification-evaporation procedure with sodium cholate as a surfactant, we prepared particles with diameters of 130-150 nm. Upon application of the appropriate stimuli, the PEtG portions of the particles degraded, resulting in partial degradation of the systems as a function of the PEtG:PLA ratio. Using Nile red as a fluorescent probe and celecoxib as a drug, it was demonstrated that the triggered PEtG depolymerization could be used to release a portion of the loaded drug, leaving the remaining drug encapsulated in the PLA phase. The fraction of rapidly released drug could be tuned based on the PEtG:PLA ratio. Celecoxibloaded PEtG particles with UV light and thiol-responsive endcaps were investigated in MDA-MB-231 breast cancer cells. Triggering of these systems with their corresponding stimuli in the presence of cells led to toxicities similar to that of free celecoxib and somewhat higher than the corresponding untriggered systems. However, differences between the triggered and untriggered systems were reduced by some background toxicity of the systems at high concentrations that likely results from the sodium cholate surfactant. In the future, 
this limitation can be mitigated by changing the surfactant, increasing the drug loadings, or using a more potent drug that requires less drug and vehicle to achieve the desired biological effect.

\section{METHODS}

General Materials and Procedures. PEtG-NVOC $\left(M_{\mathrm{n}}=\right.$ $70 \mathrm{~kg} / \mathrm{mol}, Ð=2.4)$, PEtG-BnCO $\left(M_{\mathrm{n}}=56 \mathrm{~kg} / \mathrm{mol}, Ð=1.6\right)$, and PEtG-disulfide $\left(M_{\mathrm{n}}=24 \mathrm{~kg} / \mathrm{mol}, Ð=1.4\right)$ were prepared as previously reported. ${ }^{31,38}$ Their molar mass data were obtained from size exclusion chromatography (SEC) in THF at $1 \mathrm{~mL} / \mathrm{min}$ using a Viscotek GPC Max VE2001 solvent module equipped with a Viscotek VE3580 RI detector operating at $30{ }^{\circ} \mathrm{C}$, two Agilent Polypore $(300 \times 7.5 \mathrm{~mm})$ columns, and a Polypore guard column $(50 \times 7.5 \mathrm{~mm})$. A calibration curve was obtained using polystyrene standards. Sodium cholate hydrate, GSH, DTT, Nile red, and PLA (18$28 \mathrm{~kg} / \mathrm{mol}$ ) were obtained from Sigma-Aldrich. Celecoxib was purchased from Ontario Chemicals, Inc. TGA was performed on a Q50 from TA Instruments at a heating rate of $10{ }^{\circ} \mathrm{C} / \mathrm{min}$ from 35 to $500{ }^{\circ} \mathrm{C}$ under a nitrogen atmosphere. DSC was performed using a Q2000 from TA Instruments (New Castle, $\mathrm{DE}$ ). The heating/cooling rate was $10{ }^{\circ} \mathrm{C} / \mathrm{min}$ from -75 to $+120{ }^{\circ} \mathrm{C}$. Data were obtained from the second heating cycle. Fluorescence spectra were obtained using a QM-4 SE spectrometer from Photon Technology International equipped with double excitation and emission monochromators. UVvisible spectra were obtained on a Varian UV/vis Cary 300 spectrophotometer. Ultrapure water was obtained from a Barnstead EASYpure II system. Spectra/Por regenerated cellulose membranes were used for dialysis. $0.22 \mu \mathrm{m}$ Acrodisc Syringe Filters (nonpyrogenic) with $13 \mathrm{~mm}$ diameter were used to filter particle suspensions for analysis. DLS was performed using a Zetasizer Nano ZS instrument from Malvern Instruments at $25{ }^{\circ} \mathrm{C}$ at a concentration of $0.1 \mathrm{mg} / \mathrm{mL}$ of polymer assemblies. The $Z$-average diameter and PDI index for each series of particles were measured in triplicate. TEM imaging was done using a Phillips CM10 microscope operating at an acceleration voltage of $80 \mathrm{kV}$ with a $40 \mu \mathrm{m}$ aperture. An amount of $20 \mu \mathrm{L}$ of particle suspension $(1.0 \mathrm{mg} / \mathrm{mL})$ was placed on a copper grid, and the excess liquid was wicked off with a Kimwipe. The resulting sample was air-dried for $24 \mathrm{~h}$ before imaging.

Preparation of PLA-PEtG Blends. Blends of 9:1, 7:3, and 1:1 PEtG:PLA were prepared by combining $9.0,7.0$, and $5.0 \mathrm{mg}$ of PEtG with 1.0, 3.0, or $5.0 \mathrm{mg}$ of PLA, respectively. These polymer samples were then dissolved in $\mathrm{CH}_{2} \mathrm{Cl}_{2}(1 \mathrm{~mL})$ and stirred for $30 \mathrm{~min}$ to allow for complete mixing of the polymers. The solvent was removed in vacuo for analyses.

Preparation of Particles. PEtG, PLA, or PEtG:PLA blend $(10 \mathrm{mg})$ was dissolved in $\mathrm{CH}_{2} \mathrm{Cl}_{2}(1 \mathrm{~mL})$. A separate solution of sodium cholate $(50 \mathrm{mg})$ was prepared in distilled water (10 $\mathrm{mL}$ ). The organic phase was added to the aqueous phase in a $20 \mathrm{~mL}$ glass vial. The sonication amplitude was set to $10 \%$ intensity on a Branson 450 Digital Sonifier. The biphasic mixture was then sonicated for three $30 \mathrm{~s}$ intervals with $10 \mathrm{~s}$ breaks in between for a total of $90 \mathrm{~s}$ of sonication over $120 \mathrm{~s}$. To the resulting emulsion, a magnetic stir bar was added, and the solution was vigorously stirred overnight $(16 \mathrm{~h})$ to evaporate the organic phase. After evaporation of the organic phase, the particle suspension was dialyzed $(3500 \mathrm{~g} / \mathrm{mol}$ molecular-weight cutoff (MWCO) dialysis membrane, $8 \mathrm{~h}$ ) against distilled water to remove any excess sodium cholate or trace organic solvent.

Particle Degradation Studied by DLS. Particles were prepared as described above, with the exception that the resulting suspensions were dialyzed against $100 \mathrm{mM}, \mathrm{pH} 7.4$ phosphate buffer $(1 \mathrm{~L}, 24 \mathrm{~h}$, water changed once at $\sim 12 \mathrm{~h})$. The final polymer concentration was diluted to $\sim 0.1 \mathrm{mg} / \mathrm{mL}$. The count rate was measured by DLS while fixing the attenuator at $7(t=0$ reading). For PEtG-NVOC and the $\mathrm{PEtG}-\mathrm{BnCO}$ control, irradiation with UV light was performed in an ACE Glass photochemistry cabinet containing a mercury light source ( $450 \mathrm{~W}$ bulb, $2.8 \mathrm{~mW} / \mathrm{cm}^{2}$ of UVA radiation) for $30 \mathrm{~min}$. A $t=30 \mathrm{~min}$ count rate measurement was obtained. Then the samples were incubated at $37^{\circ} \mathrm{C}$ in the dark, and the DLS count rate was measured at additional time points over 24 h. For PEtG-disulfide and the PEtG-BnCO control, DTT $(7.7 \mathrm{mmol})$ was added, and then the samples were incubated at $37^{\circ} \mathrm{C}$ in the dark. The DLS count rate was measured at various time points over $24 \mathrm{~h}$. Control experiments without stimulus were also included in each case. Each experiment was performed in triplicate.

Loading and Triggered Release of Nile Red. Nile-redloaded PEtG, PLA, or PEtG:PLA particles were prepared by the addition of Nile red $(0.1 \mathrm{mg})$ to the $\mathrm{CH}_{2} \mathrm{Cl}_{2}$ solution of PEtG or PEtG:PLA. The solution was stirred for several hours to ensure complete mixing, and then the particle preparation was performed as described above. The resulting suspensions were dialyzed against $100 \mathrm{mM}, \mathrm{pH} 7.4$ phosphate buffer. The suspensions were then diluted 10 -fold in the same buffer. Using an excitation wavelength of $540 \mathrm{~nm}$, the initial emission intensity of Nile red was measured at $602 \mathrm{~nm}$ to obtain fluorescence at T0 (starting time). At this point, the appropriate stimuli (UV light for PEtG-NVOC and DTT for PEtG-disulfide) were applied as described above for the DLS study, and the suspensions were placed in a $37{ }^{\circ} \mathrm{C}$ oven. Fluorescence measurements were taken at time points over a $24 \mathrm{~h}$ period. By comparing the fluorescence at each time point with its initial fluorescence, the percent initial fluorescence was calculated. These measurements were taken in triplicate.

Preparation of Celecoxib-Loaded Particles. Particles were prepared as described above with the addition of celecoxib (30 wt \%, $3.0 \mathrm{mg}, 7.9 \mu \mathrm{mol}$ ) dissolved in the $\mathrm{CH}_{2} \mathrm{Cl}_{2}$ phase with the polymer mixtures before sonication. After evaporation of the organic phase, the particle suspension was filtered through a pipet containing a cotton filter to remove any unloaded drug crystals. The resulting suspension was further dialyzed $(3500 \mathrm{~g} / \mathrm{mol}$ molecular-weight cutoff (MWCO) dialysis membrane, $16 \mathrm{~h})$ against distilled water $(1 \times 1 \mathrm{~L})$ to remove excess sodium cholate and any soluble free drug. Afterward, $0.1 \mathrm{~mL}$ of the particle suspension was diluted with $1.4 \mathrm{~mL}$ of acetonitrile. The absorbance of the resulting solution was measured by UV-visible spectroscopy at $253 \mathrm{~nm}$. The concentration was calculated based on a celecoxib calibration curve $(\varepsilon=16400 \mathrm{~L} / \mathrm{mol} \cdot \mathrm{cm}$, acetonitrile, $253 \mathrm{~nm})$, and the loading efficiency and drug content of the particles were calculated as follows.

$$
\begin{aligned}
& \text { Loading Efficiency }=\frac{\text { Drug Encapsulated }}{\text { Drug Added }} \times 100 \% \\
& \text { Drug wt } \%=\frac{\text { Encapsulated Drug Mass }}{\text { Mass of Polymer and Drug }} \times 100 \%
\end{aligned}
$$


Release of Celecoxib from Particles. Celecoxib-loaded particles in $\mathrm{pH} 7.4$ buffer were prepared as described above. An initial absorbance measurement was taken by removing $200 \mu \mathrm{L}$ of each sample and dissolving it in $1 \mathrm{~mL}$ of acetonitrile. Insoluble buffer salts were removed by filtration, and the absorbance was measured at $253 \mathrm{~nm}$ in order to quantify the initial amount of drug in the system. Subsequently, the appropriate stimuli were applied as described above for the DLS degradation study. The samples were then each placed in an individual $20 \mathrm{~mL}$ vial equipped with a small bar magnet, stirred at low rpm, and kept in a $37{ }^{\circ} \mathrm{C}$ oven for the duration of the study. At specified time points, each sample was centrifuged for $3 \mathrm{~min}$ at $2800 \mathrm{~g}$ to separate the precipitated drug from the suspended particles. The suspension was decanted back into the initial vial and placed back into the oven, while the pellet was dissolved in $1 \mathrm{~mL}$ of acetonitrile and the absorbance at 253 $\mathrm{nm}$ measured to quantify the amount of drug that had been released and consequently precipitated (appropriate dilutions performed to ensure an absorbance less than 1.0). This amount was compared to the initial amount of encapsulated drug in order to determine the percentage of released drug. ${ }^{1} \mathrm{H}$ NMR spectra of the pellets were obtained at $400 \mathrm{MHz}$ in $\mathrm{CD}_{3} \mathrm{CN}$ at 4 and $24 \mathrm{~h}$, to confirm the identity of the precipitated material.

In Vitro Cell Toxicity Study. Dulbecco's Modified Eagle Medium (DMEM) with $4.5 \mathrm{~g} / \mathrm{L}$ of D-glucose and $110 \mathrm{mg} / \mathrm{L}$ of sodium pyruvate was obtained from Gibco. Penicillinstreptomycin (Pen Strep, $10000 \mathrm{U} / \mathrm{mL}$ ), L-glutamine, fetal bovine serum (FBS), and trypsin-EDTA $(0.25 \%)$ were obtained from Gibco. The MDA-MB-231 cells were cultured in DMEM with $10 \mathrm{vol} \%$ FBS, 100 units $/ \mathrm{mL}$ of Pen Strep, and $2 \mathrm{mM} \mathrm{L-}$ glutamine added in an atmosphere of $5 \% \mathrm{CO}_{2}$ at $37{ }^{\circ} \mathrm{C}$. The cells were seeded in a 96-well plate (Corning Flat Bottom Plate) at a density of 10000 cells/well and allowed to adhere for $24 \mathrm{~h}$. The medium was then aspirated and replaced with varying concentrations of particles, just medium as a negative control, or sodium lauryl sulfate as a positive control. For nontriggered samples, the cells were incubated for $48 \mathrm{~h}$ with the materials. For irradiated PEtG-NVOC samples, the cells were incubated for $24 \mathrm{~h}$ with the particles and irradiated for $15 \mathrm{~min}$ with two $360 \mathrm{~nm}$ light-emitting diode (LED) flashlights (Convoy $\mathrm{S} 2+, 90 \mathrm{mMW} / \mathrm{cm}^{2}$ at a distance of $5 \mathrm{~cm}$ ), and then the cells were incubated for a further $24 \mathrm{~h}$. For GSHtriggered PEtG-disulfide samples, the cells were incubated for $24 \mathrm{~h}$ with the particles, and then $10 \mathrm{mM} \mathrm{GSH}$ was added. The cells were incubated for an additional $24 \mathrm{~h}$. Controls did not involve stimuli. The medium was then aspirated and replaced with $100 \mu \mathrm{L}$ of fresh medium containing $0.5 \mathrm{mg} / \mathrm{mL}$ of MTT reagent and allowed to react for $4 \mathrm{~h}$ in the incubator. After $4 \mathrm{~h}$ the plate was removed, and the MTT reagent solution was aspirated. An amount of $50 \mu \mathrm{L}$ of dimethyl sulfoxide was added to each well to solubilize the purple crystals. The plate was then placed in a plate reader (Tecan Infinite M1000 Pro), and the absorbance at $540 \mathrm{~nm}$ was measured to quantify the relative metabolic activities of the cells.

\section{ASSOCIATED CONTENT}

\section{S Supporting Information}

The Supporting Information is available free of charge on the ACS Publications website at DOI: 10.1021/acsomega.8b00534.

NMR spectra and SEC data for the polymers, $T_{g}$ values for polymer blends, additional DLS data, particle stability in mouse serum, drug content and loading efficiencies, photo showing particle degradation and drug precipitation, and NMR data for the centrifuged pellets from the drug release study (PDF)

\section{AUTHOR INFORMATION}

\section{Corresponding Author}

*E-mail: egillie@uwo.ca.

ORCID $\odot$

Elizabeth R. Gillies: 0000-0002-3983-2248

Notes

The authors declare no competing financial interest.

\section{ACKNOWLEDGMENTS}

We thank the Natural Sciences and Engineering Research Council of Canada (Discovery Grant 2016-04636) and the Canada Research Chair Program for funding this work.

\section{REFERENCES}

(1) Allen, T. M.; Cullis, P. R. Liposomal drug delivery systems: From concept to clinical applications. Adv. Drug Delivery Rev. 2013, 65, 3648.

(2) Blanco, E.; Shen, H.; Ferrari, M. Principles of nanoparticle design for overcoming biological barriers to drug delivery. Nat. Biotechnol. 2015, 33, 941-951.

(3) Couvreur, P. Nanoparticles in drug delivery: Past, present and future. Adv. Drug Delivery Rev. 2013, 65, 21-23.

(4) Rösler, A.; Vandermeulen, G. W. M.; Klok, H.-A. Advanced drug delivery devices via self-assembly of amphiphilic block copolymers. Adv. Drug Delivery Rev. 2012, 64 (supp), 270-279.

(5) Movassaghian, S.; Merkel, O. M.; Torchilin, V. P. Applications of polymer micelles for imaging and drug delivery. Wiley Interdiscip. Rev.: Nanomed. Nanobiotechnol. 2015, 7, 691-707.

(6) Murakami, H.; Kobayashi, M.; Takeuchi, H.; Kawashima, Y. Preparation of poly(DL-lactide-co-glycolide) nanoparticles by modified spontaneous emulsification solvent diffusion method. Int. J. Pharm. 1999, 187, 143-152.

(7) Gutiérrez, J. M.; González, C.; Maestro, A.; Solè, I.; Pey, C. M.; Nolla, J. Nano-emulsions: New applications and optimization of their preparation. Curr. Opin. Colloid Interface Sci. 2008, 13, 245-251.

(8) McCall, R. L.; Sirianni, R. W. PLGA nanoparticles formed by single-or double-emulsion with vitamin E-TGPS. J. Visualized Exp. 2013, e51015-e51015.

(9) Ma, Y.; Zheng, Y.; Zeng, X.; Jiang, L.; Chen, H.; Liu, R.; Huang, L.; Mei, L. Novel docetaxel-loaded nanoparticles based on PCL-tween 80 copolymer for cancer treatment. Int. J. Nanomed. 2011, 6, 26792688.

(10) Sun, T.; Zhang, Y. S.; Pang, B.; Hyun, D. C.; Yang, M.; Xia, Y. Engineered nanoparticles for drug delivery in cancer therapy. Angew. Chem., Int. Ed. 2014, 53, 12320-12364.

(11) Naahidi, S.; Jafari, M.; Edalat, F.; Raymond, K. N.; Khademhousseini, A.; Chen, P. Biocompatibility of engineered nanoparticles for drug delivery. J. Controlled Release 2013, 166, 182194.

(12) Göpferich, A. Mechanisms of polymer degradation and erosion. Biomaterials 1996, 17, 103-114.

(13) Mura, S.; Nicolas, J.; Couvreur, P. Stimuli-responsive nanocarriers for drug delivery. Nat. Mater. 2013, 12, 991-1003.

(14) Karimi, M.; Ghasemi, A.; Zangabad, P. S.; Rahighi, R.; Basri, S. M. M.; Mirshekari, H.; Amiri, M.; Pishabad, Z. S.; Aslani, A.; Bozorgomid, M.; Ghosh, D. Smart micro/nanoparticles in stimulusresponsive drug/gene delivery systems. Chem. Soc. Rev. 2016, 45, 1457-1501.

(15) Phillips, S. T.; DiLauro, A. M. Continuous head-to-tail depolymerization: An emerging concept for imparting amplified responses to stimuli-responsive materials. ACS Macro Lett. 2014, 3, 298-304. 
(16) Fan, B.; Gillies, E. R. Self-immolative polymers. Encycl. Polym. Sci. Technol. 2015, 1.

(17) Sagi, A.; Weinstain, R.; Karton, N.; Shabat, D. Self-immolative polymers. J. Am. Chem. Soc. 2008, 130, 5434-5435.

(18) Liu, G.; Zhang, G.; Hu, J.; Wang, X.; Zhu, M.; Liu, S. Hyperbranched self-immolative polymers (HSIPs) for programmed payload delivery and ultrasensitive detection. J. Am. Chem. Soc. 2015, 137, 11645-11655.

(19) Lewis, G. G.; Robbins, J. S.; Phillips, S. T. Phase-switching depolymerizable poly(carbamate) oligomers for signal amplification in quantitative time-based assays. Macromolecules 2013, 46, 5177-5183.

(20) Seo, W.; Phillips, S. T. Patterned plastics that change physical structure in response to applied chemical signals. J. Am. Chem. Soc. 2010, 132, 9234-9235.

(21) Kim, H.; Mohapatra, H.; Phillips, S. T. Rapid, on-command debonding of stimuli-responsive cross-linked adhesives by continuous, sequential quinone methide elimination reactions. Angew. Chem., Int. Ed. 2015, 54, 13063-13067.

(22) Fan, B.; Trant, J. F.; Yardley, R. E.; Pickering, A. J.; LagugnéLabarthet, F.; Gillies, E. R. Photocontrolled degradation of stimuliresponsive poly(ethyl glyoxylate): Differentiating features and traceless ambient depolymerization. Macromolecules 2016, 49, 7196-7203.

(23) Knoll, A. W.; Pires, D.; Coulembier, O.; Dubois, P.; Hedrick, J. L.; Frommer, J.; Duerig, U. Probe-based 3-D nanolithography using self-amplified depolymerization mechanism. Adv. Mater. 2010, 22, $3361-3365$

(24) DeWit, M. A.; Gillies, E. R. A cascade biodegradable polymer based on alternating cyclization and elimination reactions. J. Am. Chem. Soc. 2009, 131, 18327-18334.

(25) de Gracia Lux, C.; McFearin, C. L.; Joshi-Barr, S.; Sankaranarayanan, J.; Fomina, N.; Almutairi, A. Single UV or near IR triggering event leads to polymer degradation into small molecules. ACS Macro Lett. 2012, 1, 922-926.

(26) Liu, G.; Wang, X.; Hu, J.; Zhang, G.; Liu, S. Self-immolative polymersomes for high-efficiency triggered release and programmed enzymatic reactions. J. Am. Chem. Soc. 2014, 136, 7492-7497.

(27) Fan, B.; Gillies, E. R. Poly(ethyl glyoxylate)-poly(ethylene oxide) nanoparticles: Stimuli-responsive drug release via end-to-end polyglyoxylate depolymerization. Mol. Pharmaceutics 2017, 14, 25482559 .

(28) Gisbert-Garzaran, M.; Lozano, D.; Vallet-Regi, M.; Manzano, M. Self-immolative polymers as novel $\mathrm{pH}$-responsive gate keepers for drug delivery. RSC Adv. 2017, 7, 132-136.

(29) DiLauro, A. M.; Robbins, J. S.; Phillips, S. T. Reproducible and scalable synthesis of end-cap-functionalized depolymerizable poly(phthalaldehydes). Macromolecules 2013, 46, 2963-2968.

(30) DiLauro, A. M.; Lewis, G. G.; Phillips, S. T. Self-immolative poly(4,5-dichlorophthalaldehyde) and its applications in multi-stimuliresponsive macroscopic plastics. Angew. Chem. 2015, 127, 6298-6303.

(31) Fan, B.; Trant, J. F.; Wong, A. D.; Gillies, E. R. Polyglyoxylates: A versatile class of triggerable self-immolative polymers from readily accessible monomers. J. Am. Chem. Soc. 2014, 136, 10116-10123.

(32) Diesendruck, C. E.; Peterson, G. I.; Kulik, H. J.; Kaitz, J. A.; Mar, B. D.; May, P. A.; White, S. R.; Martínez, T. J.; Boydston, A. J.; Moore, J. S. Mechanically triggered heterolytic unzipping of a low-ceilingtemperature polymer. Nat. Chem. 2014, 6, 623-628.

(33) Kaitz, J. A.; Moore, J. S. Functional phthalaldehyde polymers by copolymerization with substituted benzaldehydes. Macromolecules 2013, 46, 608-612.

(34) Kaitz, J. A.; Moore, J. S. Copolymerization of o-phthalaldehyde and ethyl glyoxylate: Cyclic macromolecules with alternating sequence and tunable thermal properties. Macromolecules 2014, 47, 5509-5513.

(35) Chen, E. K. Y.; McBride, R. A.; Gillies, E. R. Self-immolative polymers containing rapidly cyclizing spacers: Toward rapid depolymerization rates. Macromolecules 2012, 45, 7364-7374.

(36) DeWit, M. A.; Beaton, A.; Gillies, E. R. A reduction sensitive cascade biodegradable linear polymer. J. Polym. Sci., Part A: Polym. Chem. 2010, 48, 3977-3985.
(37) Olah, M. G.; Robbins, J. S.; Baker, M. S.; Phillips, S. T. Endcapped poly(benzyl ethers): Acid and base stable polymers that depolymerize rapidly from head-to-tail in response to specific applied signals. Macromolecules 2013, 46, 5924-5928.

(38) Fan, B.; Trant, J. F.; Gillies, E. R. End-capping strategies for triggering the end-to-end depolymerization of polyglyoxylates. Macromolecules 2016, 49, 9309-9319.

(39) DiLauro, A. M.; Abbaspourrad, A.; Weitz, D. A.; Phillips, S. T. Stimuli-responsive core-shell microcapsules with tunable rates of release by using a depolymerizable poly(phthalaldehyde) membrane. Macromolecules 2013, 46, 3309-3313.

(40) Fan, B.; Trant, J. F.; Hemery, G.; Sandre, O.; Gillies, E. R Thermo-responsive self-immolative nanoassemblies: Direct and indirect triggering. Chem. Commun. 2017, 53, 12068-12071.

(41) Peterson, G. I.; Church, D. C.; Yakelis, N. A.; Boydston, A. J. 1, 2-oxazine linker as a thermal trigger for self-immolative polymers. Polymer 2014, 55, 5980-5985.

(42) Lewis, G. G.; Robbins, J. S.; Phillips, S. T. Point-of-care assay platform for quantifying active enzymes to femtomolar levels using measurements of time as the readout. Anal. Chem. 2013, 85, 1043210439.

(43) Monks, T. J.; Jones, D. C. The metabolism and toxicity of quinones, quinonimines, quinone methides, and quinone-thioethers. Curr. Drug Metab. 2002, 3, 425-438.

(44) Baker, P. R. S.; Cramer, S. D.; Kennedy, M.; Assimos, D. G.; Holmes, R. P. Glycolate and glyoxylate metabolism in hepg2 cells. Am. J. Physiol. Cell Physiol. 2004, 287, C1359-1365.

(45) Belloncle, B.; Bunel, C.; Menu-Bouaouiche, L.; Lesouhaitier, O.; Burel, F. Study of the degradation of poly(ethyl glyoxylate): Biodegradation, toxicity and ecotoxicity assays. J. Polym. Environ. 2012, 20, 726-731.

(46) Cheng, R.; Feng, F.; Meng, F.; Deng, C.; Feijen, J.; Zhong, Z. Glutathione-responsive nano-vehicles as a promising platform for targeted intracellular drug and gene delivery. J. Controlled Release 2011, $152,2-12$.

(47) Ding, J.; Chen, J.; Li, D.; Xiao, C.; Zhang, J.; He, C.; Zhuang, X.; Chen, $\mathrm{X}$. Biocompatible reduction-responsive polypeptide micelles as nanocarriers for enhanced chemotherapy efficacy in vitro. J. Mater. Chem. B 2013, 1, 69-81.

(48) Saito, G.; Swanson, J. A.; Lee, K. D. Drug delivery strategy utilizing conjugation via reversible disulfide linkages: Role and site of cellular reducing activities. Adv. Drug Delivery Rev. 2003, 55, 199-215.

(49) Kuppusamy, P.; Li, H.; Ilangovan, G.; Cardounel, A. J.; Zweier, J. L.; Yamada, K.; Krishna, M. C.; Mitchell, J. B. Noninvasive imaging of tumor redox status and its modification by tussue glutathione levels. Cancer Res. 2002, 62, 307-312.

(50) Liu, X.; Zou, Y.; Li, W.; Cao, G.; Chen, W. Polym. Degrad. Stab. 2006, 91, 3259-3265.

(51) Greenspan, P.; Mayer, E. P.; Fowler, S. D. Nile red: A selective fluorescent stain for intracellular lipid droplets. J. Cell Biol. 1985, 100, 965-973.

(52) Krishna, M. M. G. Excited-state kinetics of the hydrophobic probe nile red in membranes and micelles. J. Phys. Chem. A 1999, 103, 3589-3595.

(53) Jendrossek, V. Exploiting celecoxib in cancer therapy. In Mitochondria: The Anti-Cancer Target for the Third Millenium; Neuzil, J., Pervaiz, S., Fulda, S., Eds.; Springer: Dordrecht, 2014; pp 105-133.

(54) Jendrossek, V. Targeting apoptosis pathways by celecoxib in cancer. Cancer Lett. 2013, 332, 313-324.

(55) De Vecchis, R.; Baldi, C.; Di Biase, G.; Ariano, C.; Cioppa, C.; Giasi, A.; Valenta, L.; Cantatrione, S. Cardiovascular risk associated with celecoxib or etoricoxib: A meta-analysis of randomized controlled trials which adopted comparison with placebo or naproxen. Minerva Cardioangiol. 2014, 62, 437-448.

(56) Mantry, P.; Shah, A.; Sundaram, U. Celecoxib associated esophagitis: Review of gastrointestinal side effects from cox-2 inhibitors. J. Clin. Gastroenterol. 2003, 37, 61-63. 